\title{
An isoquinoline alkaloid, Protopine from Corydalis govaniana growing in Himalayan region of Nepal
}

\author{
R.L.(Swagat) Shrestha ${ }^{1^{*}}$ and R.N.Jha ${ }^{2}$ \\ ${ }^{1}$ Department of Chemistry, Tri-Chandra Campus, Tribhuvan University, Kathmandu, Nepal. \\ ${ }^{2}$ Department of Chemistry, Amrit Campus, Tribhuvan University, Kathmandu, Nepal.
}

Email: swagatstha@hotmail.com

\begin{abstract}
Chemical investigation of the roots of Corydalis govaniana resulted in the isolation and characterization of one isoquoniline alkaloid, protopine(1). The structure was established on the basis of extensive spectroscopic data analysis and comparison with spectroscopic data reported.
\end{abstract}

Key words: Corydalis govaniana, Fumariaceae, Isoquinoline alkaloid.

\section{Introduction}

Corydalis govaniana Wall (Fumariaceae) is glabrous herb and is distributed in Himalayas of Pakistan, India and in Eastern, Central and Western part of Nepal. It grows in damp and shady places at 2400 to $4800 \mathrm{~m}$ attitude $^{1}$. A number of medicinal values have been reported in Indian and Chinese systems of medicine for corydalis species ${ }^{2-4}$. The root of Corydalis govaniana is used during diarrhea and dysentery $^{2}$. Previous studies on Corydalis govaniana led to the isolation of many isoquinoline alkaloids ${ }^{5,6,7}$. Owing to its unusual geographical location, it was decided to analyze the plants in terms of its alkaloidal content. Our study of a Corydalis govaniana has resulted in the isolation and characterization of one isoquinoline alkaloid (1).

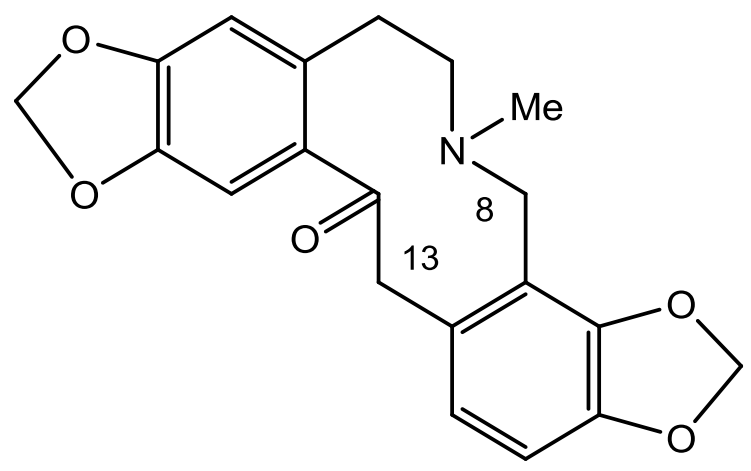

Figure 1: Protopine : 4,6,7,14-Tetrahydro-5-methylbis[1,3]benzodioxolo[4,5-c:5',6'-g]azecin-13(5H)-one

\section{"Corresponding author}




\section{Experimental}

The melting point was determined on a Toshniwal apparatus and uncorrected UV spectrum was recorded with Perkin-Elmer Lambde spectrophotometer using spectral methanol. An IR spectrum was recorded in $\mathrm{KBr}$ pellets. ${ }^{1} \mathrm{HNMR}$ spectra were recorded in $500 \mathrm{MHz}$ in deuterated acetone using tetra methyl silane (TMS) as internal reference. Mass spectrum was performed on JEOL mass spectrometers operating at $70 \mathrm{eV}$. The purity of substance was checked on TLC plates.

The roots of Corydalis govaniana was collected from Langtang, Nepal and identified by comparison with the authentic herbarium specimen at the National Herbarium Laboratory, Kathmandu, Nepal. Airdried roots of Corydalis govaniana $(2 \mathrm{~kg})$ was extracted with methanol for seven days in cold percolator. After removal of methanol under reduced pressure, the residue $(354.30 \mathrm{gm})$ was treated with $7 \%$ citric acid and separated to alkaloid fraction according to the procedure of R.N. Jha et.al. ${ }^{8}$

The fraction obtained using above procedure was analyzed on TLC for alkaloids by spraying with Dragendorff's reagent. The chloroform extract $(41.12 \mathrm{gm})$ was chromatographied over silica-gel column using solvent of increasing polarity. The eluants from $\mathrm{C}_{6} \mathrm{H}_{6}$ : Acetone (1:1) were mixed and solvent removed to give crude product which was re-chromatographied over silica-gel column to get pure compound which on crystallization from methanol yield $20 \mathrm{mg}$ of compound (1).

Compound 1: M.P. $207^{\circ}-208^{\circ} \mathrm{C}$, uv $\lambda \max (\mathrm{MeOH}) 293 \mathrm{m \mu}$, IR $\left(\mathrm{KBr}, \mathrm{cm}^{-1}\right) 1675,{ }^{1} \mathrm{HNMR}$ (in Table 1), 2D NMR in figure $1(2), \mathrm{ms}(\mathrm{m} / \mathrm{z}, \%), 353(10) 148(100)$ (Scheme -1)

Table: $1500 \mathrm{MHz}{ }^{1} H N M R$ spectral data of Compound 1 in Acetone

Chemical shift

Proton count
Splitting pattern
Probable assignment

$\begin{array}{cccc}2.04-3.83 & 8 \mathrm{H} & \underline{\mathrm{m}} & \mathrm{C}-5-\mathrm{H} 2, \mathrm{C}-6-\mathrm{H} 2, \mathrm{C}-8-\mathrm{H} 2, \& \mathrm{C}- \\ 5.93 & 2 \mathrm{H} & \underline{\mathrm{s}} & 13-\mathrm{H} 2 \\ 5.97 & 2 \mathrm{H} & \underline{\mathrm{s}} & \mathrm{CH}_{2} \mathrm{O}- \\ 6.91 & 1 \mathrm{H} & \underline{\mathrm{s}} & \mathrm{CH}-\mathrm{O}- \\ 6.63 & 1 \mathrm{H} & \underline{\mathrm{s}} & \mathrm{C}-4-\mathrm{C}-\mathrm{H} \\ 6.72 & 1 \mathrm{H} & \underline{\mathrm{d}} & \mathrm{C}-11-\mathrm{H} \\ 6.78 & 1 \mathrm{H} & \underline{\mathrm{d}} & \mathrm{C}-12-\mathrm{H} \\ 1.88 & 3 \mathrm{H} & \underline{\mathrm{s}} & \mathrm{N}-\mathrm{CH}_{3}\end{array}$




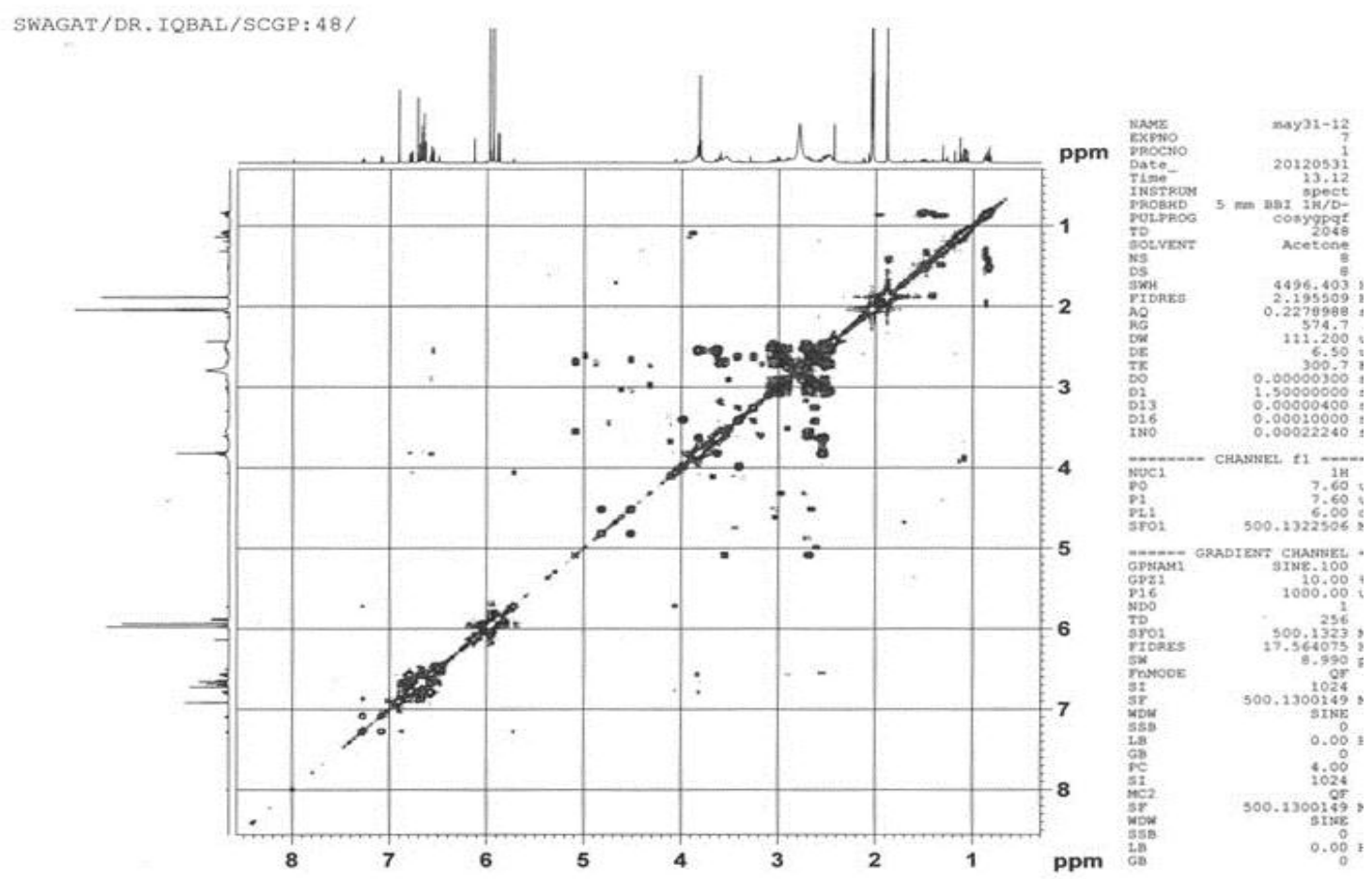

Figure 2: $2 D \mathrm{NMR} / \mathrm{COSY}$

\section{Result and Discussion}

The compound (1) was obtained as colourless granules. The molecular formula of compound based on the high resolution mass spectrum was found to be $\mathrm{C}_{20} \mathrm{H}_{19} \mathrm{NO}_{5} ; \mathrm{m} / \mathrm{z} 353\left(\mathrm{M}^{+}\right), 148$ (base peak). A fragmentation pattern indicative of protopine could be easily rationalized (scheme 1). The ultraviolet spectrum in $\mathrm{MeOH}$ showed absorption maxima at $293 \mathrm{m \mu}$ like that of isoquinoline alkaloids ${ }^{9}$. The IR spectrum contained an absorbance at $1675 \mathrm{~cm}^{-1}$ indicating the presence of a trans annular ground state interaction between the carbonyl and the basic nitrogen, so that the carbonyl group in appreciably of the amide type; $0=\mathrm{C} \leftarrow \mathrm{N}-\mathrm{CH}_{3}$. The ${ }^{1} \mathrm{HNMR}$ spectrum of 1 (Table-1) showed the following; two methylene dioxy group at 25.93 and 5.97 (each $2 \mathrm{H} \mathrm{S}$ ); two aromatic protons as singlet at 26.91 and 6.63; two coupled aromatic protons as doublet at 6.78 and 6.72; one $\mathrm{N}$-methyl group at $21.88(3 \mathrm{H}, \mathrm{S})$; four aliphatic protons as multiplet at 2.04-3-83. Its structure was also favored by 2D NMR. Based on above evidence, the structure of $\mathbf{1}$ was determined (Fig.1) and named as protopine. Further structure of this compound was confirmed by the comparison with reported data ${ }^{10,11}$. 


\section{Conclusion}

The structure of compound $\mathbf{1}$ was established by physical, chemical and spectroscopic data. The physical constant and spectroscopic data ( IR, UV, NMR, MS) of the base were identical to those of protopine. This is the first report of the occurrence of protopine in Corydalis govaniana growing in Himalayan region of Nepal.

\section{Scheme 1}
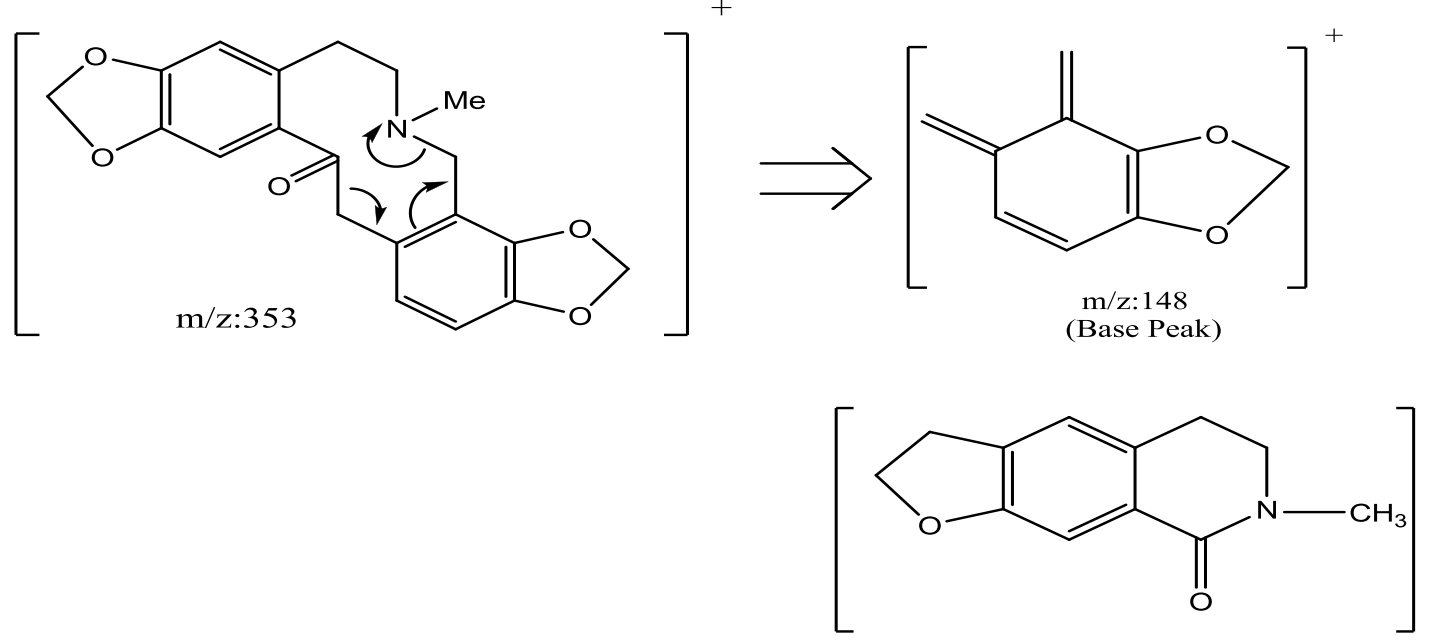

$\mathrm{m} / \mathrm{z}: 206$

\section{Acknowledgement}

The authors are thankful to Prof. Dr. M. I. Choudhary and Asst. Prof. Dr. Achyut Adhikari, University of Karachi for spectral analysis. The authors are also thankful to Nepal Academy of Science and Technology(NAST) for financial support and special thanks to Department of Chemistry, TriChandra College and Amrit Campus.

\section{References}

1. Flowers of the Himalaya, Oleg Polunin and Adam Stainton, Oxford, University Press, 1984, 32.

2. The wealth of India, Raw materials, CSIR, New Delhi, India, 1950, II, 358

3. W.Tang and G.Eisenbrand, Chinese Drugs of plant origin, Springer Verley, New York, 1992, 377.

4. M.Liden, Rheedea, 1995, 5, 2

5. S.Mukhopadhyay, S.Banergee, and C.K.Atal, J. Nat. Prod., 1987, 50(2), 270.

6. O.E.Edwards and K.L.Handa, Can. J. Chem., , 1961,39,1801.

7. K.Mehra, H.S.Garg, D.S.Bhakuni and N.M.Khana, Ind.J.Chem., 1976, 14B, 844.

8. R.N.Jha, M.B.Pandey, A.K.Singh and V.P.Singh, J.Nat.Prod.Res., 2009, 23(3), 250.

9. M.Sharma, The Isoquinoline alkaloids, Academic Press, New York,1972,352.

10. E.B. Harssen \& H.C. Chiang, J.Org. Chem., 1977, 35, 88.

11. C.K.Yu, D.B. MacLean, R.G.A. Rodrigo \&R. H. F. Manske, Can. J. Chem. 1970, 40, 3673. 